\title{
Magallanes, Graciela; Gandía, Claudia y Vergara, Gabriela Comp. (2015): Expresiones/Experiencias en tiempos de Carnaval. Análisis desde las sensibilidades y la estructuración social. Buenos Aires: Ciccus. 264 pp. ISBN: 978-987-693-113-7.
}

La portada del libro Expresiones/experiencias en tiempos de carnaval. Análisis desde las sensibilidades y la estructuración social, compilado por Graciela Magallanes, Claudia Gandía y Gabriela Vergara, lleva como fondo un vivo color rojo sobre el cual se puede ver un collage de fotografías y un río pintado con acuarelas. Estos elementos visuales sirven como pistas acerca de lo que el lector podrá encontrar a lo largo de los escritos que componen el libro, cuyo énfasis se plantea alrededor de la unidad dialéctica que conforman expresiones y experiencias en el proceso barrial de organización, preparación, puesta a punto y desarrollo de actividades carnavalescas. De tal modo que, fotografías, dibujos, colores, vestuarios, movimientos corporales, prácticas musicales y videos, son presentados como accesos para el estudio sociológico de las sensibilidades en las ciudades de Villa María y Villa Nueva, en la provincia de Córdoba, Argentina.

De entrada, el libro indica que su énfasis no es el carnaval, sino lo que en él acontece configurando un espacio en el que se pueden evidenciar diferentes modos de las relaciones interpersonales e intergrupales. En este sentido, el carnaval conlleva en sus pliegues, no solamente dinámicas relativas a la espectacularización, mercantilización e institucionalización del evento, sino también a las esperanzas, disputas, disrupciones y pasiones que son susceptibles de una tematización crítica. En este caso, el abordaje es resultado de procesos de reflexión e indagación sostenidos por el Grupo de Estudios Sociales sobre Subjetividades y Conflictos (GESSYCO) de la Universidad Nacional de Villa María, cuyos integrantes han mantenido diálogos con espacios académicos de las ciudades de Córdoba y Buenos Aires -todo en articulación con las actividades del Centro de Investigaciones y Estudios Sociológicos (CIES)-.

El libro, en su introducción, es presentado metafóricamente como un regalo, lo que permite pensar y jugar con (al menos) tres dimensiones reflexivas: -la primera, señalada en las primeras páginas del texto, resalta una invitación a desenvolver, a desempacar, alentando al lector en el ejercicio del descubrir, -la segunda puede pensarse en términos maussianos, destacando las implicancias del regalar (del don) en conexión con los sentidos y lazos sociales que cuestiona-estimula cada capítulo, -la última, que ubica al acto de regalar como práctica intersticial, en contraste con las inercias capitalistas que propenden continuamente hacia el ahogamiento de la acción basada en la reciprocidad ${ }^{1}$. Estas dimensiones se hacen patentes en el entramado teórico, metodológico y analítico que los capítulos dinamizan y que dejan ver un trabajo grupal consistente.

Aunque el libro orbita metodológicamente en torno a los denominados Encuentros-CreativosExpresivos (en adelante ECE), diferentes técnicas de recolección de datos fueron empleadas en el proceso investigativo: encuestas, entrevistas individuales y grupales, observación participante y no participante, y registro de documentos primarios y secundarios. Cada capítulo del libro llama la atención acerca de "encontrarse con estrategias metodológicas que implican otras formas de analizar e interpretar la densidad de aquello que esta concentrado en lo que los sujetos no dicen con palabras" (p. 16). En esta línea, se deja claro que los ECE consisten en un dispositivo que permite adentrarse al ámbito pre-predicativo de la sociedad estudiada -incorporando el uso de colores, dibujos, collages y videos-; es en sintonía con los ECE que las demás técnicas son entendidas para explorar sentidos corporales y emocionales. De tal forma, el lector podrá encontrar la aplicación de una propuesta metodológica enfocada fundamentalmente hacia el estudio de las sensibilidades sociales.

De forma complementaria, es posible reconocer, dentro de los referentes teóricos de este trabajo, la influencia de autores como Giddens, Habermas, Mellucci o Bourdieu, entre otros. A lo que se suma la apuesta por la construcción y formulación de avances en términos de una sociología de los cuerpos/emociones -asunto ligado a trabajos previos en los que han participado las compiladoras ${ }^{2}$. Tanto los conceptos como los elementos metodológicos están encaminados al tratamiento de la cotidianidad social en la cual se figuran dinámicas disruptivas, prácticas intersticiales, que hacen parte de la construcción y realización del carnaval en medio de

\footnotetext{
1 Scribano, A. (2014): "El don: entre las prácticas intersticiales y el solidarismo", Sociologias, 16(36): 74103.

2 Magallanes, G., Gandía, C. y Vergara, G. (2014): Expresividad, creatividad y disfrute. Buenos Aires: Estudios Sociológicos Editora; Scribano, A., Magallanes, G. y Boito, M. (2012): La fiesta y la vida. Estudio desde una sociología de las prácticas intersticiales. Buenos Aires: Ciccus.
} 
tensiones, distensiones, contradicciones y concordancias grupales/individuales.

Si bien los capítulos de esta compilación refieren a expresiones/experiencias que convergen en un evento festivo, cada uno de ellos desarrolla una perspectiva temática propia. Así, el lector podrá encontrar: -un recorrido por el uso de datos visuales en las ciencias sociales, -una reflexión sobre la sintonización social a través del tatuaje en la piel de los integrantes de las batucadas, -un análisis sobre el color, los dibujos y las emociones como canales de acceso al ámbito de las sensibilidades sociales, -una presentación introductoria sobre la expresividad culinaria del migrante, -una teorización sobre creatividad, disfrute y formas expresivas ligadas a la intersticialidad, -una mirada analítica sobre los collages elaborados, en los ECE, por los jóvenes de las comparsas, -una digresión sobre el orgullo, la resignación y la vergüenza en la marginalidad, -una mirada sobre las percepciones que recaen sobre un barrio humilde, $y$, finalmente, -una introducción teórica sobre algunos elementos conceptuales propuestos por Giddens para pensar el sentido creativo del "salir adelante" en las acciones colectivas.

Veamos con más detalle el contenido del libro. El primer capítulo, escrito por Claudia Gandía, ofrece una reconstrucción del uso de datos visuales para la figuración de conocimiento en las ciencias sociales. Gandía resalta el lugar de la imagen como Source

Source de información, como medio expresivo y como canal metodológico, que constituye un espacio válido para la indagación sobre las sensibilidades colectivas. Esta propuesta reconoce el trabajo previo que sobre el tema han adelantado autores como Goffman, Becker, Benjamín, Bourdieu, Barthes, Mead y Bateson, a partir de los cuales señala la necesidad de "afloja[r] las ataduras a determinados modelos como los únicos posibles para generar conocimiento" (p. 44), claro, buscando justificar el uso que en la propuesta metodológica global del libro tiene el trabajo con imágenes (yendo más allá del ámbito puramente verbal).

El segundo capítulo, de Federico Díaz Llorente, se concentra en el tema de los tatuajes, como una continuación del asunto de la imagen, esta vez inscripta en los cuerpos y que puede indicar sentidos de vida en conexión (compartidos por los carnavaleros). En este caso se recurre a la idea de sintonía mutua propuesta por Alfred Schutz para destacar una trama ligada a lo sonoro y lo visual que se hace evidente en la piel de las personas que integran las batucadas. Los tatuajes permiten al autor, señalar un flujo vivencial y afectivo que funciona como intersticialidad más allá de una conceptualización prefigurada o expresada verbalmente.

De forma complementaria, el tercer capítulo, escrito por Gabriela Vergara, trabaja sobre los ECE, en los que "un plexo de diversas técnicas [...] se entrelazan para captar sensibilidades a partir de actividades expresivas mediante el uso de colores, la creación de collages junto con registros e instancias de intercambios colectivos" (p. 68). El capítulo se concentra específicamente en el tema del color usado en los dibujos, como medio de acceso a las emociones que son descritas con palabras, pero que también son evidentes en los gestos y posturas corporales. Vergara igualmente interpela al lector acerca de las formas de conceptualizar lo emocional, reclamando la necesidad de combinar explicaciones sociales sin olvidar los factores biológicos en juego.

De otro lado, Julia Bertone, en el cuarto capítulo, nos cuenta sobre el carnaval boliviano en Villa Nueva, resaltando el componente alimenticio que atraviesa dicha festividad. En este caso, el consumo de alimentos deja ver, no solo una forma material relativa a la presentación de los platos y el componente energético que ellos implican, sino también unos sentidos simbólicos con peso identitario. De tal manera, es posible hablar de una expresividad culinaria que potencia al "nosotros migrante" y que busca afirmarse en el nuevo territorio, allí el alimento es un factor clave de la estructuración grupal.

Seguidamente, Graciela Magallanes y Claudia Gandía, en el quinto capítulo, abordan el tópico de la expresividad, tratando de encontrar sus conexiones con la creatividad y el disfrute, resaltando cómo en la festividad se figuran prácticas intersticiales. Las autoras sostienen que la estructura social no sólo es medio sino también resultado de las prácticas (sensu Giddens), y que en este marco se desarrollan las experiencias y dinámicas conflictuales. Así, "[l]os bienes y usufructos que se disfrutan en esas prácticas [del carnaval] ponen de manifiesto procesos de apropiación, expropiación, donde se solapan los conflictos inscriptos en el proceso de estructuración social" (p. 122). Es en este marco que las autoras proponen un ejercicio conceptual con las ideas de disfrute, plus y gozo, para explorar una mirada más profunda sobre lo que denominan "juegos de relaciones creativas".

En el sexto capítulo encontramos el trabajo de Rebeca Cena y Gabriela Vergara, éste aborda los collages desarrollados, en el marco de los ECE, junto a jóvenes integrantes de las comparsas y batucadas. Las autoras se apoyan en elementos teóricos referidos a la creatividad (tomados de Sartre, Vigotsky y Torrance) y a la expresividad (tomados principalmente de von Herder). En este caso lo expresivo juega un papel central que "da cuenta del estado de compresión de las sensaciones reguladas y de los mecanismos que hacen soportable la vida cotidiana" (p. 146), a la vez que "lo expresivo se considera una vía que conecta con las redes conflictuales que se generan en la estructuración capitalista" (p. 147). Cena y Vergara detallan una construcción del objeto de análisis (las sensibilidades) a través del uso de videos, colores, collages y opiniones/reflexiones de los participantes y problematizan el hecho de encontrarse frente a sentidos colectivos que se presentan como estandarizados y programados.

En el capítulo siete, de Vanina Freire, encontramos un acercamiento al estudio del orgullo y la resignación 
como estados emocionales ligados a la vergüenza, buscando proponer un reconocimiento de dimensiones afectivas a través de la territorialidad en lo barrial y reflexionando sobre expectativas, amenazas y tensiones sociales latentes en medio de experiencias de marginalidad. Freire hace uso de datos estadísticos alusivos al índice de necesidades básicas insatisfechas en un barrio villamariense y contrasta tales datos con entrevistas realizadas a miembros del barrio, a partir de ello la autora explora rasgos sensibles conectados a la antigüedad en el territorio y sus efectos en el orgullo individual.

En el último tramo, el capítulo ocho, escrito por Lucas Aimar y Alejandra Peano, ofrece un marco de contextualización socioeconómica de Villa María haciendo énfasis en las experiencias y percepciones de los habitantes del barrio Los Olmos. Los autores recurren a entrevistas en las que se cruzan ideas de territorialización, cotidianidad y segregación social, ubicando la mirada en los modos de habitar un lugar como contraste frente a la fantasía de una ciudad pulcra y organizada. Allí el disfrute, que se evidencia en las dinámicas vivenciales del carnaval, puede ser interrogado en sus conexiones con una estructura mercantil.

Finalmente, el noveno capítulo, de Francisco Falconier, desarrolla una mirada panorámica sobre el pensamiento de Giddens en lo relativo a la relación entre individuo y sociedad para pensar el lugar del sujeto en la estructuración social (del agente y la fuerza que le impone la estructura grupal en sus ritmos de vida). El capítulo, al igual que los dos que le preceden, se concentra en el caso del barrio villamariense de Los Olmos, en dicho contexto resalta experiencias del "salir adelante" que se asientan en acciones creativas individuales en medio del tejido de acciones colectivas. A la par, se intenta reconocer cómo la confianza es una fuente favorable para el avance de prácticas intersticiales que son conjugadas en el entramado barrial.

El libro incluye, además, a modo de epílogo, el proyecto que sirvió de base para el trabajo investigativo y cuyos resultados son expuestos a largo de los diferentes capítulos. Este material de cierre es muy útil para entender los antecedentes teóricoprácticos del grupo, complementar los componentes conceptuales de los artículos y conocer las proyecciones que de este ejercicio académico se desprenden. El libro puede considerarse como un material de consulta obligatoria para todos aquellos interesados en el estudio de las sensibilidades sociales, no sólo por las posibles reflexiones que cada capítulo alienta, sino especialmente por el collage analítico que allí se configura y por la exposición explícita del uso de una metodología potente para abordar el ámbito de los cuerpos/emociones.

Rafael Sánchez Aguirre Consejo Nacional de Investigaciones Científicas y Técnicas. Centro de Investigaciones y Estudios Sociológicos, Argentina rasaguirre@gmail.com

Recibida: 12-09-2016 Aceptada: 05-10-2016 